Gazi University
Journal of Science
http://dergipark.gov.tr/gujs

\title{
Effect of Deposition Temperature on the Properties of Copper-Zinc Sulphide Thin Films using Mixed Copper and Zinc Dithiocarbamate Precursors
}

\author{
Joseph Onyeka EMEGHA ${ }^{1}$ (D), Kingsley Eghonghon UKHUREBOR ${ }^{2, *}$ (D) Uyiosa Osagie AIGBE $^{3}$ (D), Bolutife \\ OLOFINJANA $^{4}$, Samuel Ogochukwu AZI ${ }^{1}$ (i) , Marcus Adebola ELERUJA ${ }^{4}$ \\ ${ }^{1}$ Department of Physics, Faculty of Physical Sciences, University of Benin, P.M.B. 1154, Benin City, Nigeria \\ ${ }^{2}$ Department of Physics, Edo State University Uzairue, P.M.B. 04, Auchi, 312101, Edo State, Nigeria. \\ ${ }^{3}$ Department of Mathematics and Physics, Cape Peninsula University of Technology, P.O. Box 1906, Cape Town, South Africa \\ ${ }^{4}$ Department of Physics and Engineering Physics, Obafemi Awolowo University, Ile-Ife, 220005, Nigeria

\section{Highlights} \\ - Single solid source precursor is a novel technique in thin-film fabrication. \\ - Single solid source precursor reduces the limitations with multiply source ones. \\ - Deposition temperature influences the copper-zinc sulphide thin films. \\ - Material thin films are useful for solar energy generation.
}

Article Info

Received: 26 Feb 2021

Accepted: 19 Oct 2021

Keywords

Deposition temperature

Electrical properties

Optical properties

Precursor

Thin-films

\begin{abstract}
The influence of deposition temperatures on the structural, elemental, optical and electrical properties was investigated. The Rutherford backscattering (RBS) and scanning electron microscopy (SEM) were used to measure the elemental and morphological properties of the films. The RBS confirms that the stoichiometry was controlled by the deposition temperatures with a thickness that ranged between 51.00 to $63.00 \mathrm{~nm}$. SEM data of the deposited films show different morphologies with several grains that increased with deposition temperature. Optical characterization shows that the films exhibited a direct transition with an energy gap that varies from 1.79 to $2.10 \mathrm{eV}$. For copper-zinc sulphides (CZS) film deposited at $470{ }^{\circ} \mathrm{C}$, the maximum electrical conductivity was $7.38 \times 10^{-2}(\Omega . \mathrm{cm})^{-1}$ and minimum electrical resistivity was $1.35 \times 10^{1}$ $(\Omega . \mathrm{cm})$. The results confirm the possibility of using copper and zinc dithiocarbamate precursors in depositing high-quality CZS thin films with comparable properties.
\end{abstract}

\section{INTRODUCTION}

The study of material thin films has become a crucial part of science and technology due to their practical applications. Though their thermodynamics are difficult to comprehend, it has been majorly exploited in spintronics and optoelectronics devices. There are also numerous and growing applications in optical electronics, communications, coatings of various kinds, solar cells etc [1-3]. Among all the proposed applications of material thin films, energy generation (solar cells) is the most attractive form due to its advantages over fossil fuels. As a clean and renewable source of energy, the number of injuries and death arising from the effect of pollution due to incomplete combustion of fossil fuels is reduced [4]. Unfortunately, their relative low efficiencies and high cost of production make them less competitive than the conventional (fossil) source of energy [5].

In recent years, advances in solar cells of high efficiencies, enhanced stability and low cost of production have initiated intensive research activities into new materials and different technological approaches to thin films deposition. Copper zinc sulphides (CZS) have shown unique desirability due to the possibility of turning their energy gap and other physical properties for device applications. Furthermore, the energy gap lies between copper sulphides $(\mathrm{CuS})$ and zinc sulphides $(\mathrm{ZnS})$ which can be adjusted by varying the ratio 
of zinc $(\mathrm{Zn})$ and copper $(\mathrm{Cu})$ in the ternary system. This striking energy gap of CZS films influences their usage in the fabrication of p-n junction solar cells [6]. Some well-established thin films deposition methods with their corresponding starting precursors like chemical bath deposition, spray pyrolysis, electron beam evaporation, electrochemical atomic layer deposition, solution growth technique and SILAR have been reported for depositing CZS thin films [1,3]. These methods utilize two or more precursors with diverse possessions that may affect the quality and functionality of the films [7]. Uhuegbu and Babatunde [8] used copper chloride, zinc nitrate and thiourea as precursors to deposit CZS thin film while Rosado-Mendoza and Oliva [9] used zinc sulphate, copper chloride and thiourea as precursors for $\mathrm{Zn}, \mathrm{Cu}$ and sulphur (S) respectively to determine the influence of $\mathrm{Cu}$ concentration on the properties of $\mathrm{ZnS}$ thin films using chemical bath deposition method. The same method was utilized by Ortiz-Ramos et al. [10] using copper sulphate, zinc acetate and dimethyl sulphate.

There are several reported developed techniques for the synthesis of such nanostructures/thin films. These techniques are divided into two classes; vapor-phase (V-P) synthesis and solution-phase (S-P) synthesis. The V-P synthesis procedures are chemical vapor deposition (CVD), metal-organic CVD (MOCVD), thermal evaporation, as well as catalyst aided laser ablation. All these procedures are executed at a high temperature with a manageable diameter, composition, and morphology of the nanostructures [11].

Although considerable studies have been reported on CZS thin films; however, there is a limited report on the influences of deposition temperature on the properties of CZS films using the MOCVD technique via a single solid source precursor. The use of a single solid source precursor (dithiocarbamate) in the film's production provides a novel technique in thin-film material fabrication with the advantages of reducing the shortcomings arising from using multiply sources of precursors $[12,13]$. Hence, this study outlines the influence of varying deposition temperatures on the structural, elemental, morphological, optical and electrical properties of the MOCVD fabricated CZS thin films. The variation in the temperature was to determine if there were structural or morphological changes in the synthesised material. The other sections of this article are structured as follows: Section two discusses the materials and method (experimentation), section three contains the results and discussion, while section four is the concluding part of the paper.

\section{MATERIAL METHOD}

\subsection{Synthesis of Dithiocarbamate Complexes}

Copper dithiocarbamate $\left(\mathrm{CuC}_{10} \mathrm{H}_{16} \mathrm{~N}_{2} \mathrm{O}_{2} \mathrm{~S}_{4}\right)$ and zinc dithiocarbamate $\left(\mathrm{ZnC}_{10} \mathrm{H}_{16} \mathrm{~N}_{2} \mathrm{O}_{2} \mathrm{~S}_{4}\right)$ complexes were prepared as outlined in literature [3].

\subsection{Thin Films Deposition and Characterization}

The CZS films were deposited on clean (soda-lime) substrates employing the MOCVD method. The dried precursors of copper dithiocarbamate and zinc dithiocarbamate were mixed (50:50) and made into a fine powder. The dithiocarbamate powder was passed into a precursor holder and nitrogen gas was pumped through the set-up at a rate of $2.0 \mathrm{dm}^{3} / \mathrm{min}$. The precursor in the nitrogen gas medium was subsequently moved to the deposition chamber of the furnace through a long glass tube-powered electrically. The precursor sublime first on getting to the furnace, thereafter, thermal decomposition of the CZS films on the substrates at different temperatures of 370, 400, 430 and $470{ }^{\circ} \mathrm{C}$. Figure 1 shows the experimental set-up of CZS thin films deposition [14]. 


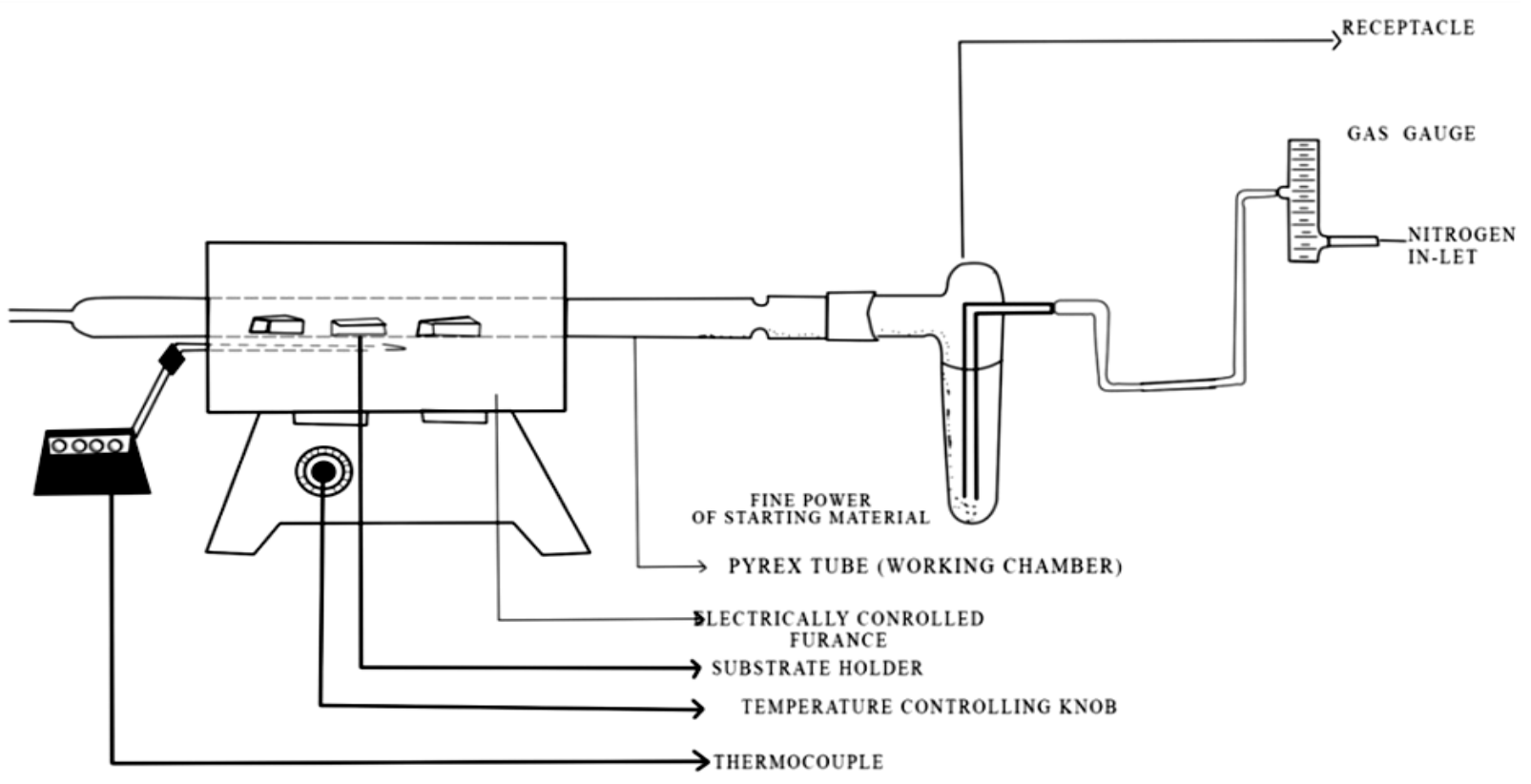

Figure 1. Experimental set-up for CZS deposition

The structural characterization of the film was measured utilizing a "D8-High Resolution X-ray diffractometer" with a wavelength of $\lambda=1.5406 \AA$. Elemental compositions and thickness of the deposited films were observed by "Rutherford Backscattering Spectroscopy (RBS)" techniques using 2.2 MeV Tandem Accelerator. The surface morphology of the films was analysed utilizing "JEOL JSM-7600F Scanning electron microscopy (SEM)" operated at a voltage of 1000 V. Double beam UV-1800 Shimadzu Spectrophotometer was used to observe the optical properties while four-point probes were employed for the electrical properties' determination.

\section{RESULTS AND DISCUSSION}

\subsection{Structural Analysis}

The deposited films were compared against the X-ray diffraction (XRD) pattern of $\mathrm{ZnS}, \mathrm{CuS}$ and their complex oxides [15]. Figure 2 shows the XRD measurement of CZS thin films with deposition temperatures. The XRD measurement at $370^{\circ} \mathrm{C}$ revealed that the films were polycrystalline in nature with major peaks at $2 \theta=21.90^{\circ}(211), 27.02^{\circ}(111), 48.80^{\circ}(220)$ and $56.38^{\circ}(311)$ (Figure 2a). The peak at 370 ${ }^{\circ} \mathrm{C}$ is similar to the standard sphalerite $\mathrm{ZnS}$ thin films (JCPDS 050566, JCPDS 36-1450). As the deposition temperature moves to $400{ }^{\circ} \mathrm{C}$, there were steady formations of additional peaks at $2 \theta=33^{\circ}(200), 37.76^{\circ}$ (400) and $58.20^{\circ}$ (311) (Figure 2b). These peaks were also associated with the sphalerite ZnS thin films. However, the intensity of the peaks was found to be gradually decreasing with an increase in deposition temperature, which indicates a progressive transformation of the CZS oriented polycrystalline phase to a distinct $\mathrm{ZnS}$ phase. This shows a separation from the deposited CZS thin films to $\mathrm{ZnS}$ with increasing deposition temperature [16-20]. Increasing the deposition temperature from 400 to $430{ }^{\circ} \mathrm{C}$ reveals that the deposited material suddenly changes to polycrystalline ZnO (JCPDS 36-1451) with different peaks orientation. This result can be attributed to the chemical reaction between the film's precursors and the MOCVD chamber, producing a chemically new phase formation of $\mathrm{ZnO}$ over $\mathrm{ZnS}$ thin films. Moreover, the formation of $\mathrm{ZnO}$ thin films is thermodynamically favoured over $\mathrm{ZnS}, \mathrm{CuS}$ or $\mathrm{Cu}_{2} \mathrm{O}$ having a higher heat of formation [21].

At $470{ }^{\circ} \mathrm{C}$, the typical $\mathrm{ZnS}$ structure reappears with higher numbers of peaks and intensities. This separation of the deposited ternary CZS film to ZnS thin films demonstrates the fact that the ionic radius of $\mathrm{Zn}^{2+}$ $(0.74 \AA)$ and $\mathrm{Cu}^{2+}(0.73 \AA)$ are very close and therefore can coexist and displace each other without much distortion to the CZS matrix. Therefore, CZS thin films can appear as $\mathrm{ZnS}$ and $\mathrm{ZnO}$ due to temperature 
modifications as indicated in the XRD measurements. Similar XRD observations were outlined by Alkhayatt et al. [1] and Jose and Kumar [15] for CZS thin films using another route.

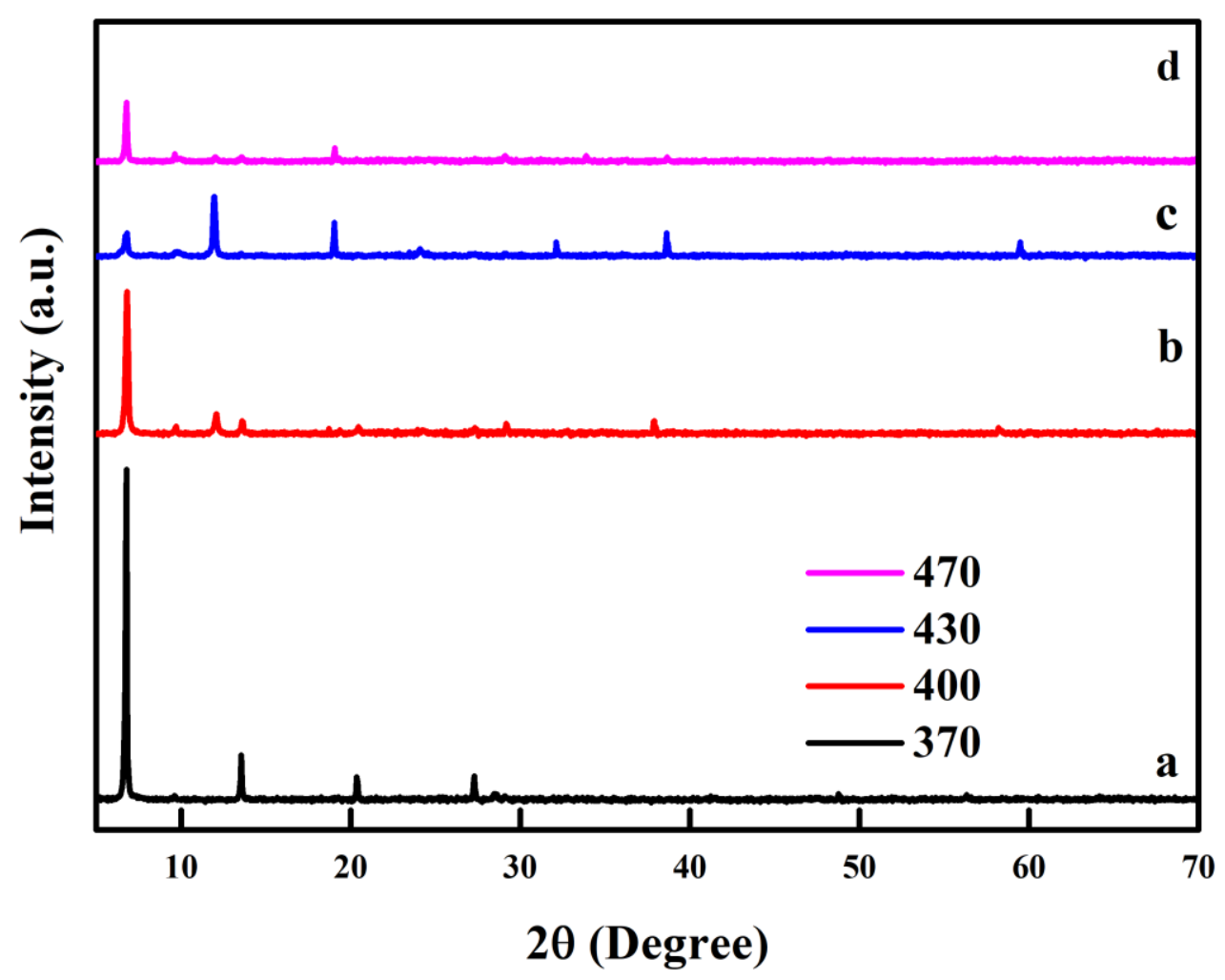

Figure 2. XRD spectrum of CZS films at (a) $370{ }^{\circ} \mathrm{C}$, (b) $400{ }^{\circ} \mathrm{C}$, (c) $430^{\circ} \mathrm{C}$, and (d) $470^{\circ} \mathrm{C}$

The average crystalline or grain size (Dn) was calculated using Debye-Scherrer's Equation:

$D_{n}=\frac{k \lambda}{\beta \cos \theta}$

where $\mathrm{k}$ is the shape factor, $\lambda$ is the X-ray wavelength, $\beta$ is the full-width half-maximum (FWHM) in radians, and $\cos \Theta$ is the cosine of the Bragg angle [22].

The calculated Dn were $81.20 \mathrm{~nm}, 42.96 \mathrm{~nm}, 44.98 \mathrm{~nm}$ and $53.48 \mathrm{~nm}$ for $370{ }^{\circ} \mathrm{C}, 400{ }^{\circ} \mathrm{C}, 430{ }^{\circ} \mathrm{C}$ and 470 ${ }^{\circ} \mathrm{C}$ respectively. This shows that the Dn varies with different temperatures and there was a reduction in Dn as the temperature was increased from $370{ }^{\circ} \mathrm{C}$ to $470{ }^{\circ} \mathrm{C}$, but the reduction was more evident when the temperature was increased from $370{ }^{\circ} \mathrm{C}$ to $400{ }^{\circ} \mathrm{C}$.

Figure 3 shows the RBS spectrum of the films deposited on soda-lime substrates. The spectrums depict two recognizable sections of the thin film and the substrate section. The characteristic proportions of $\mathrm{Zn}, \mathrm{Cu}$ and $\mathrm{S}$ in the film section are observed, and the summary of the elemental analysis is indicated in Table 1. However, it was observed that the elemental composition values ( $\mathrm{Cu}, \mathrm{Zn}$ and $\mathrm{S}$ elements) were less than $100 \%$ except for the film deposited at $400{ }^{\circ} \mathrm{C}$. This discrepancy could as a result of the presence of impurities within the deposited CZS thin films within the various temperatures. The impurities could result from the interactions of the films with the substrates (soda-lime glass), as well as the increase in deposition temperature and the various deposition processes during synthesis [11]. It clearly shows (from Table 1), that the intensity of $\mathrm{S}$ increases with the addition of deposition temperatures. This could be an indication of the possible disintegration of the complex bonds of the precursors and the steady reformation of the bonds, resulting in several attained stoichiometry at the various deposition temperatures 
[23]. In addition, it was observed that the ratio of $\mathrm{S} /(\mathrm{Cu}+\mathrm{Zn})$ in the films was not constant, which suggest that the CZS film is non-stoichiometric. It is reasonable to assume that the increase in deposition temperature raises the rate of nucleation of atoms in the precursor and, after that, the elements in the CZS system [24]. Notably, the ambiguity in the XRD analysis (presence of $\mathrm{ZnS}$ and $\mathrm{ZnO}$ instead of CZS), was reconciled with the RBS studies. The RBS measurement showed that the elemental compositions of the deposited material consist of $\mathrm{Cu}, \mathrm{Zn}$ and $\mathrm{S}$ as indicated in Table 1. Furthermore, the peaks of these elements $(\mathrm{Cu}, \mathrm{Zn}$ and $\mathrm{S})$ were distinguished by the $\mathrm{He}^{+}$beam and used to estimate the linear thickness using the information about the material density as follows $[3,24]$ :

Thickness $(\mathrm{nm})=\frac{\text { atom per unit area }}{\text { atom per unit volume }}$.

However, in [25] the authors only worked on the variation of concentrations on CZS thin films at a constant deposition temperature of $400^{\circ} \mathrm{C}$. While in the present study, the major concern was about the influence of varying deposition temperatures in the synthesis of $\mathrm{CuZnS}$ at constant concentrations. The measured thickness of the deposited films from the RBS analysis is given in Table 1. It was observed that the thickness grows from 51 to $63 \mathrm{~nm}$ with addition in deposition temperature from 370 to $470{ }^{\circ} \mathrm{C}$. The possible reason for this increase in thickness with temperature could be the increased kinetic process taking place within the MOCVD chamber as the deposition temperature was increased, resulting in the rearrangement of the molecules of the precursor within the films. Hence, the thickness increases with an increase in deposition temperature [26]. According to the RBS analysis, the deposition temperature does not only influence the thickness but also the morphological, optical as well as electrical properties.
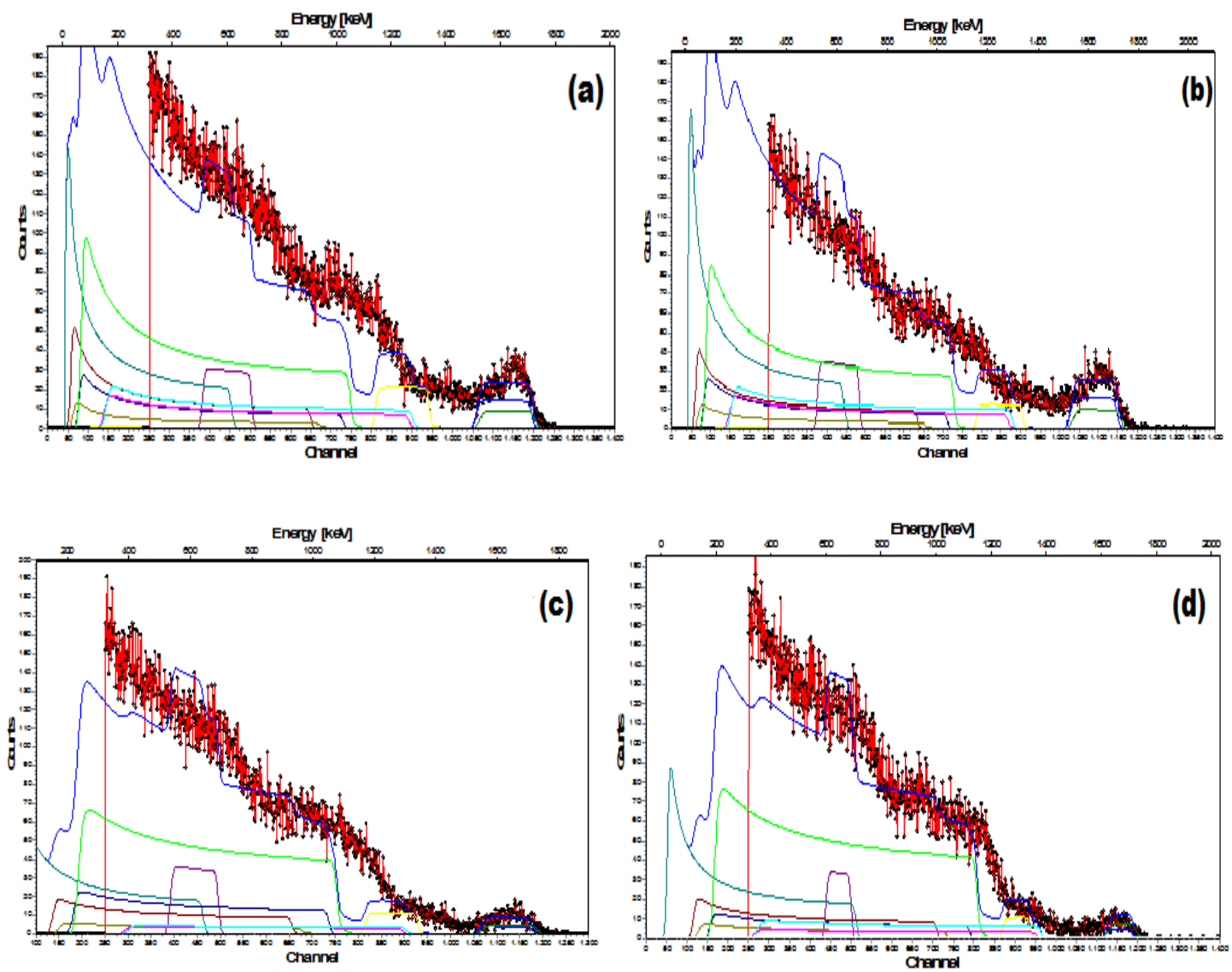

Figure 3. RBS spectrum of CZS films at (a) $370^{\circ} \mathrm{C}$, (b) $400{ }^{\circ} \mathrm{C}$, (c) $430^{\circ} \mathrm{C}$, (d) $470{ }^{\circ} \mathrm{C}$ 
Table 1. Summary of the RBS analysis of CZS films

\begin{tabular}{cccccc}
\hline $\begin{array}{c}\text { Deposition Temperature } \\
\left({ }^{\circ} \mathrm{C}\right)\end{array}$ & \multicolumn{2}{c}{ Elemental Composition $(\%)$} & $\mathrm{S} /(\mathrm{Cu}+\mathrm{Zn})$ & Thickness \\
\hline 370 & $\mathrm{Cu}$ & $\mathrm{Zn}$ & $\mathrm{S}$ & & $(\mathrm{nm})$ \\
\hline 400 & 21.4 & 21.7 & 56.0 & 1.30 & 51 \\
430 & 22.4 & 21.4 & 56.2 & 1.28 & 54 \\
470 & 20.1 & 19.7 & 59.2 & 1.49 & 60 \\
\hline
\end{tabular}

The variations in surface morphology with deposition temperatures are shown in Figure 4. It can be observed that the substrates were well covered with films of different morphological structures. For 370 ${ }^{\circ} \mathrm{C}$, the SEM micrograph shows cloudy images, which indicates a partial grains formation within the films. This result suggests that the heat at $370{ }^{\circ} \mathrm{C}$ is insufficient for the whole development of the CZS grains. Increasing the deposition temperature to $400{ }^{\circ} \mathrm{C}$, it was observed that the films were rougher with the formation of some compact grain-like features. Evidently, the gradual formation of grain-like features was due to the increased nucleation rate as the deposition temperature is increased.

Further increase in deposition temperature from $400{ }^{\circ} \mathrm{C}$ to $430{ }^{\circ} \mathrm{C}$, increased the formation of the grains. Therefore, maintaining the non-uniform and close-packed morphology over the substrate. Some pore-like crystalline holes were also found to develop on the surface of the films as the temperature increases. In addition, the increased formations of black and white grains were also observed. These grains (black and white) originated from the variation of $\mathrm{Zn}$ and $\mathrm{Cu}$ content within the $\mathrm{CZS}$ matrix as the deposition temperature is elevated. This may explain the coexistence of $\mathrm{Zn}$ and $\mathrm{Cu}$ in the $\mathrm{CZS}$ system as indicated from the XRD and RBS measurements. However, these larger grains were found to detach into smaller and well-organized quasi-spherical polycrystalline grains at $470^{\circ} \mathrm{C}$. This development is in agreement with the fact that increasing the deposition temperature results in a number of grains diffusing and coalescing simultaneously to form sizable crystalline grains with defined crystallographic morphologies as revealed from the SEM studies. A similar observation was as well reported by Efe et al. [23] for CZS thin films. Furthermore, the different morphological structures exhibited by this material may be the direct result of the different phases and elemental compositions of the film suggested from the XRD and RBS studies. 

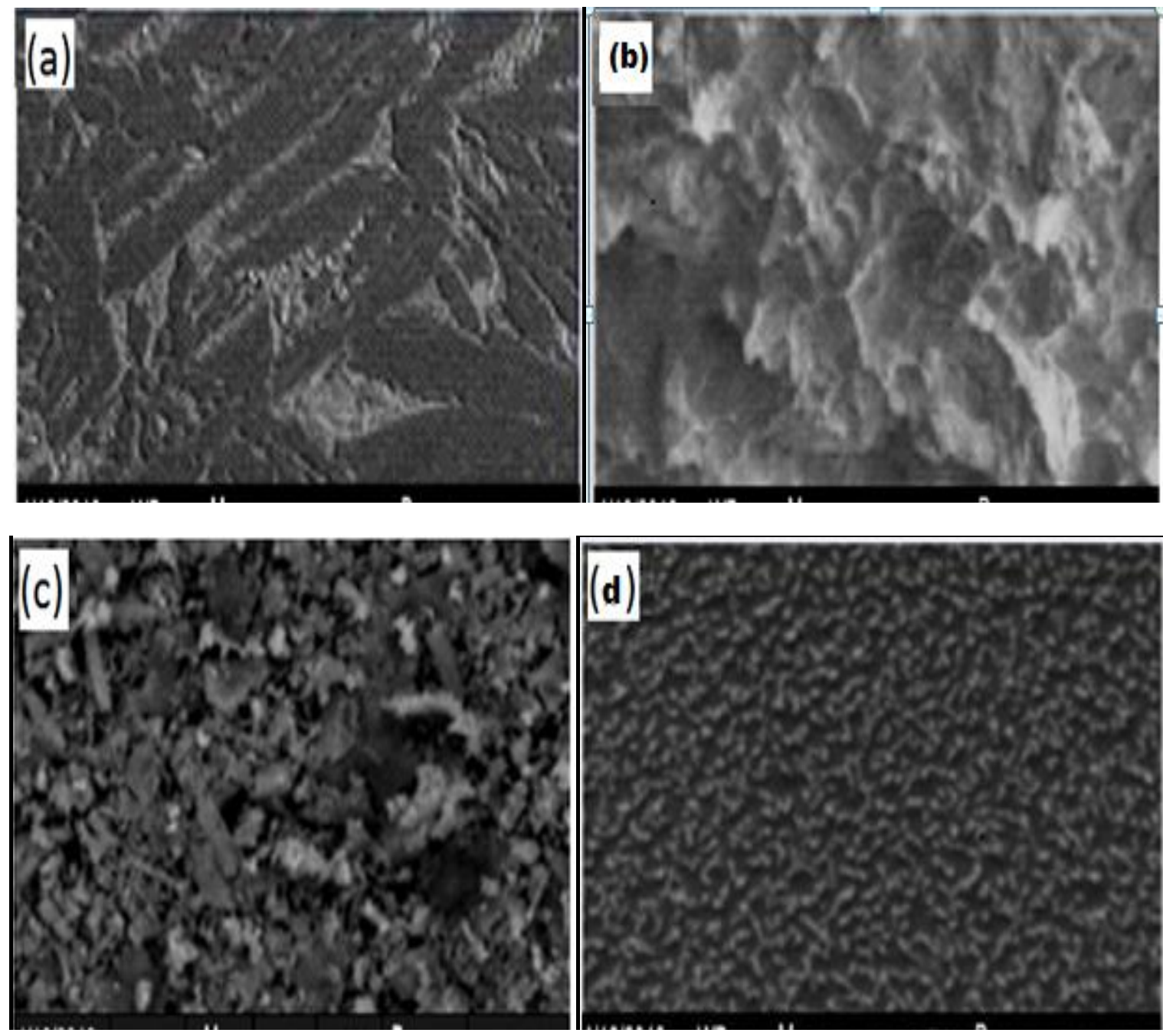

Figure 4. SEM micrograph of CZS films at (a) $370^{\circ} \mathrm{C}$, (b) $400^{\circ} \mathrm{C}$, (c) $430^{\circ} \mathrm{C}$, (d) $470^{\circ} \mathrm{C}$

\subsection{Optical Studies of CZS Films}

To determine the suitability of CZS thin films for various applications, the absorbance (A) was determined using the relationship in Equation (3):

$$
\mathrm{A}=\log \frac{1}{T}
$$

where $T$ is the transmittance and $\mathrm{A}$ is the absorbance. Figure 5 shows the optical absorbance spectrum of the deposited CZS thin films. It was observed (from Figure 5), that the absorbance decreases with deposition temperature. Also, the value of the optical absorbance was found to be higher in the UV region and decreases down the regions. This, however, implies an enhancement in the transmission of the films. This improvement in absorption for CZS material is due to the substantial development in the crystallinity with deposition temperature as observed from the structural analyses. This demonstrates that CZS is a suitable material for UV filter production, where high absorption of UV radiation is needed [27]. The optical band gap was estimated using the following relationship in Equation (4) [28, 29]:

$\alpha=\frac{B}{h v}[h v-E \mathrm{opt}]^{m}$

where $\alpha$ is the absorption coefficient, $B$ is a constant, $h$ is the Plank's constant, $v$ is frequency, and $E_{\text {opt }}$ is the energy gap. In Equation (3), the electronic transition factor is represented by $\mathrm{m}$. Since CZS thin film is a direct bandgap semiconductor, $\mathrm{m}$ assumes the value of 0.5 [3]. The graph of $(\alpha \mathrm{h} v)^{2}$ against $h v$ for CZS 
thin films at various deposition temperatures is presented in Figure 6. The energy gap $\left(E_{\text {opt }}\right)$ was obtained by extrapolating the linear part of the graph to intercept the $h v$ axis at $\alpha=0$. The bandgap obtained varies from 1.79 to $2.10 \mathrm{eV}$ with deposition temperatures increase as shown in Table 2.

These values fall within the band-gap range for CZS thin films reported in various literatures [14,26,30,31]. The reduction in the energy gap may be due to an improvement in structural crystallinity or phase transformation taking place within the films as a result of increased deposition temperatures as indicated from the XRD and SEM measurements [32]. Also, it could be due to the direct effect of reduction in transition tail width and shift effect within the carrier concentration [7]. This observed decrease in the bandgap with an increase in deposition temperatures improves the optical properties of the material and make them possible as window layers material in solar cell fabrication since the highest number of photons ensuing from solar radiation have wavelength in the visible and near-infrared regions of the electromagnetic wave $[23,27]$. The calculated band-gap values in this study are to some extent less than that described by Rosado-Mendoza and Oliva [9] and Ortiz-Ramos et al. [10]. However, the difference may be a result of the MOCVD method used in the CZS thin films production.

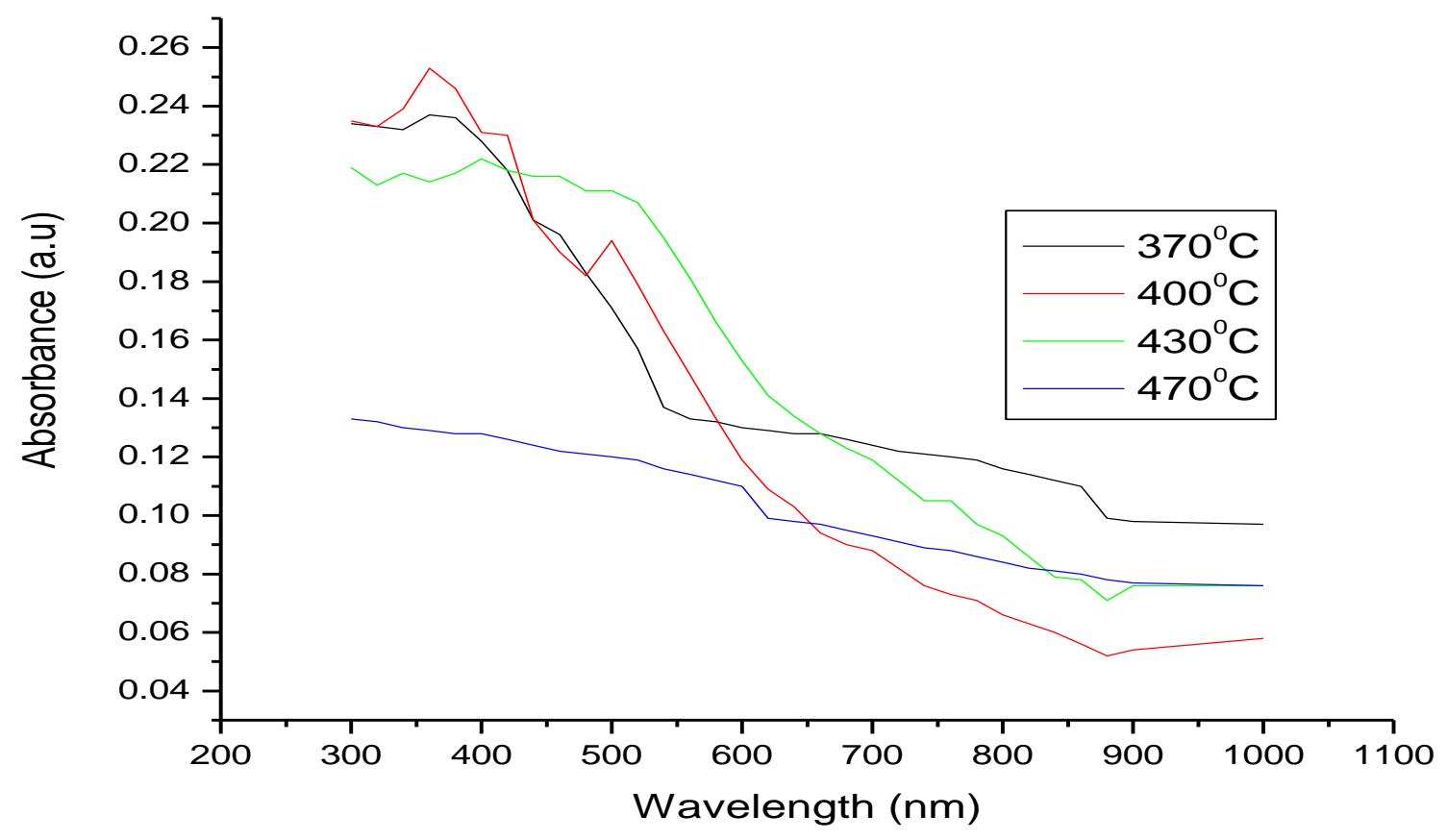

Figure 5. Absorbance versus wavelength at different deposition temperatures 

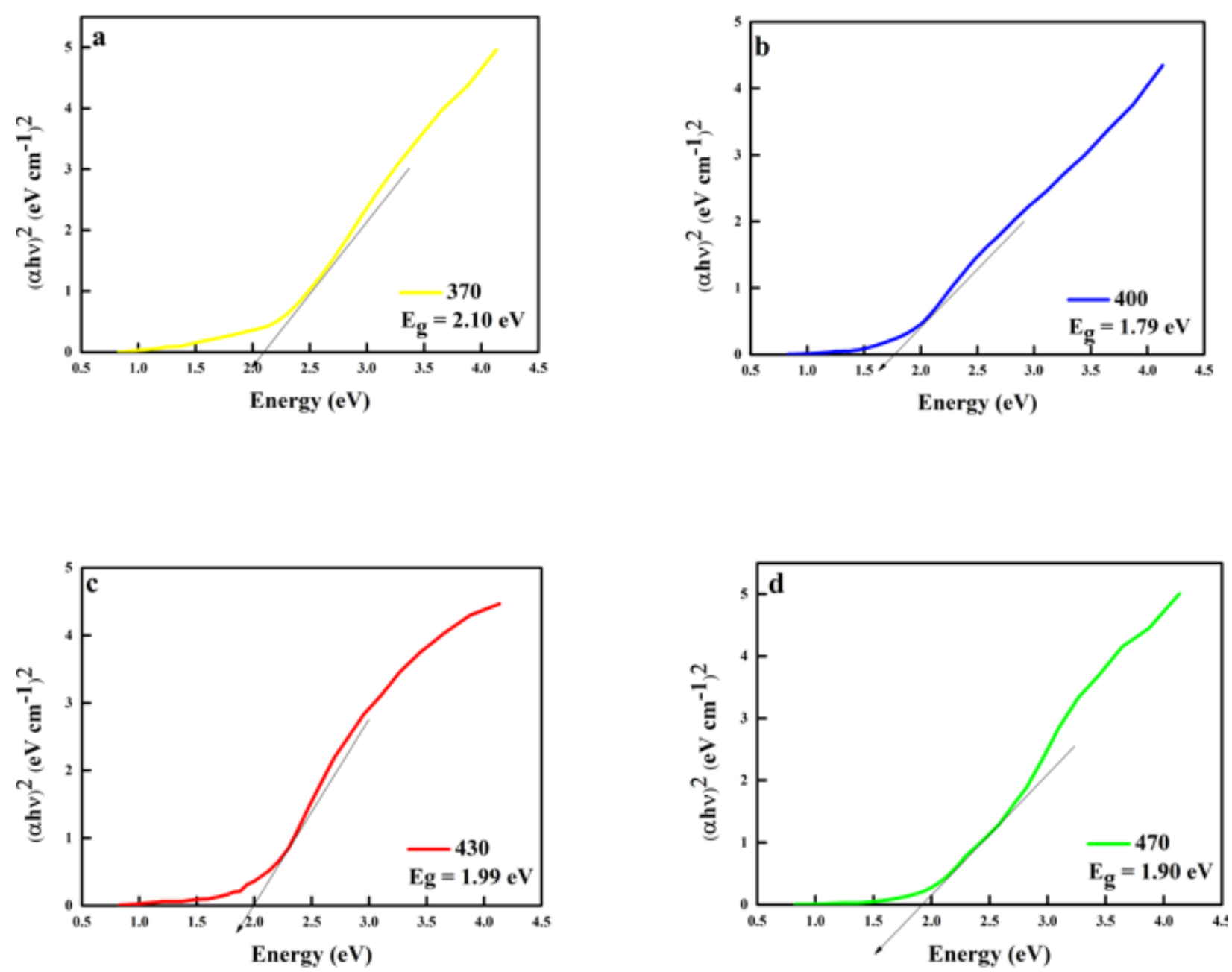

Figure 6. Square of absorption coefficient versus photo energy of CZS films

Table 2. Values of energy gap, refractive index, extinction coefficient, resistivity and conductivity of CZS films

\begin{tabular}{lcllll}
\hline $\begin{array}{l}\text { Deposition } \\
\text { temperature }\left({ }^{\circ} \mathrm{C}\right)\end{array}$ & $\begin{array}{c}\text { Energy gap } \\
(\mathrm{eV})\end{array}$ & $\begin{array}{l}\text { Refractive } \\
\text { index }(\mathrm{n})\end{array}$ & $\begin{array}{l}\text { Extinction } \\
\text { coeff. } \times 10^{-3}\end{array}$ & $\begin{array}{c}\text { Resistivity } \\
(\Omega \mathrm{cm})\end{array}$ & $\begin{array}{l}\text { Conductivity } \\
(\Omega . \mathrm{cm})^{-1} \times 10^{-2}\end{array}$ \\
\hline 370 & 2.10 & 1.99 & 9.14 & 29.53 & 3.39 \\
400 & 1.79 & 1.84 & 7.32 & 28.30 & 3.53 \\
430 & 1.99 & 1.92 & 8.36 & 14.04 & 7.12 \\
470 & 1.90 & 1.81 & 6.20 & 13.55 & 7.38 \\
\hline
\end{tabular}

The refractive index (n) and extinction coefficient are two fundamental optical parameters of CZS thin films on account of their relationship to the electronic polarization of the optical materials. These parameters are strongly influenced by the wavelength of electromagnetic radiation and, thus, are important materials in optical communication, switches and solar cells device applications. The refractive index (n) of the material was estimated using the expression in Equation (5) [33,34]:

$\mathrm{n}=\left(\frac{1+R}{1-R}\right)+\sqrt{\frac{4 R}{(1-R)^{2}}-K^{2}}$.

Here, $R$ represents the reflectance, $K$ is the extinction coefficient $(K=\alpha \lambda / 4 \pi)$ and $\alpha$ is the absorption coefficient [35-39]. Figure 7 indicates the graphical representation of the variation of the refractive index with wavelength. As noticed from Figure 7, the refractive index was high in the UV- regions and decrease linearly to the near-infrared regions with deposition temperatures. This indicates that the films dispersion 
is dependent on the deposition temperatures. It is also observed that the average values of the refractive index vary with deposition temperatures as shown in Table 2 . The reason for this variation in the refractive index comes from the successive internal reflection and the various excitations taking place within the films as the deposition temperature changes. This observation dovetails nicely with the result outlined by Uhuegbu et al. [30], for CZS thin films via solution growth technique.

The average values of the extinction coefficient have been listed in Table 2 and presented graphically in Figure 8, against the photo-energy. The graphical representation reveals that the extinction coefficient is increasing with deposition temperatures for all the films. Overall, the films displayed low extinction coefficients over the energy range. Consequently, there was a loss in the very low absorption energy in the wavelength regions. This trend in the extinction coefficient is similar to those reported by Damisa et al. [7].

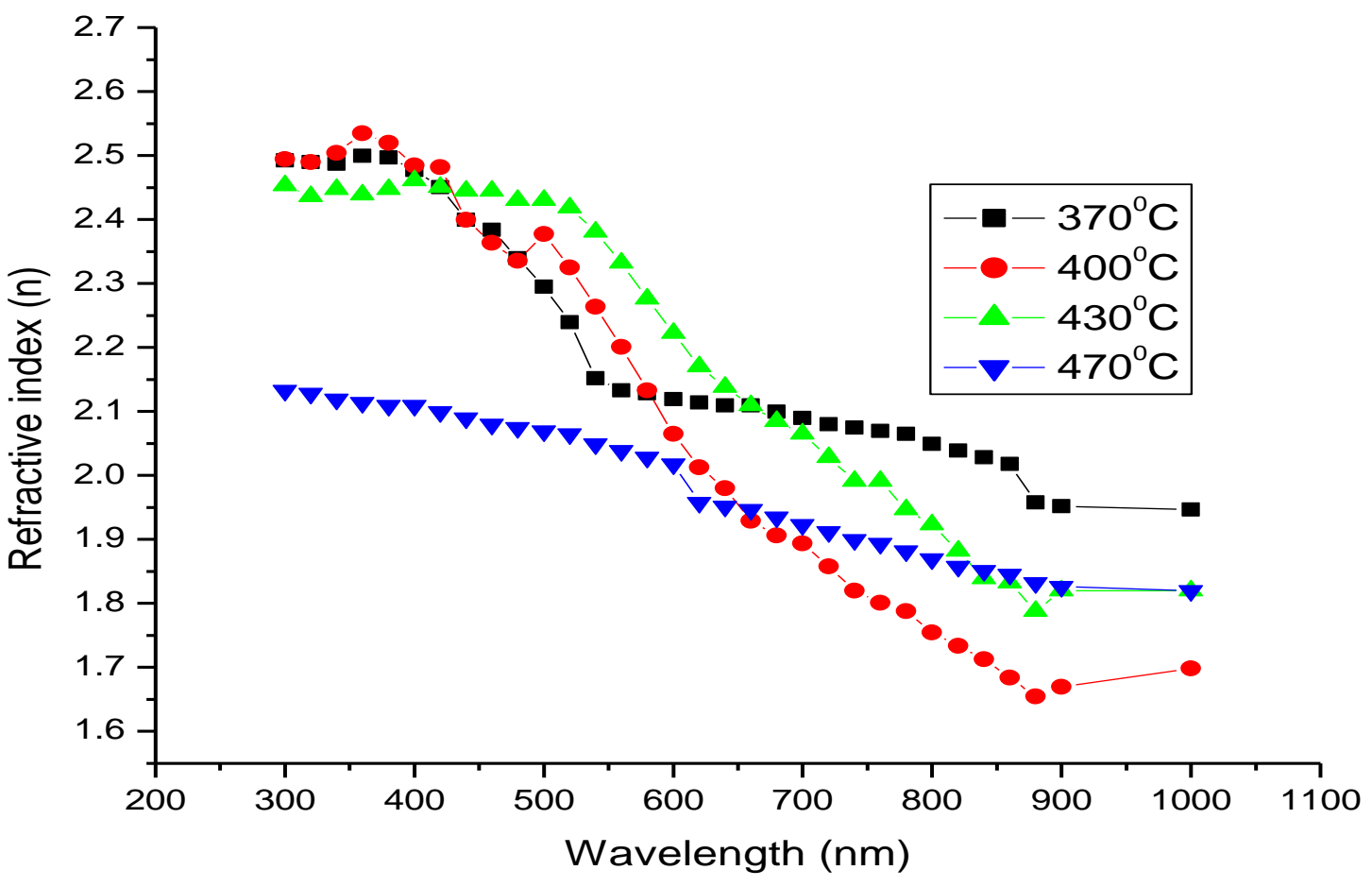

Figure 7. Refractive index against wavelength of CZS films 


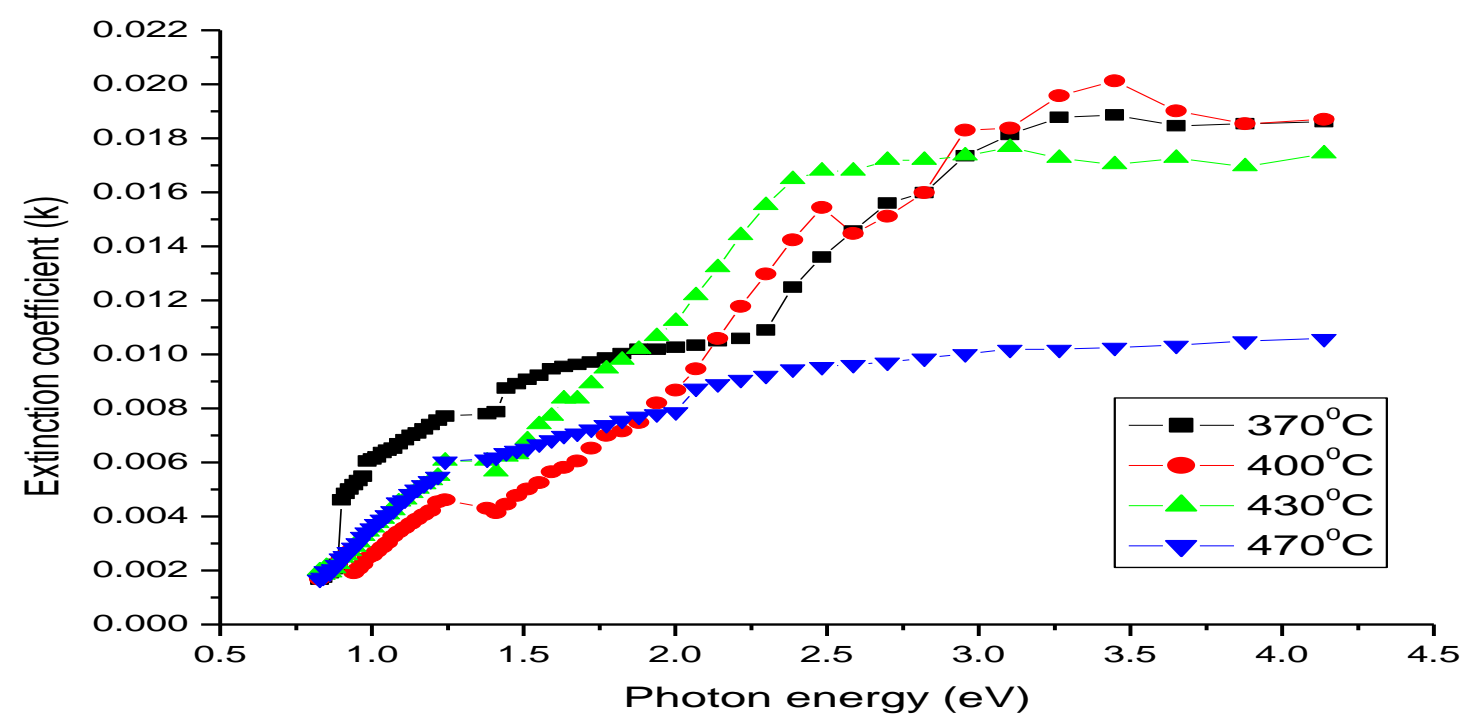

Figure 8. Extinction coefficient versus photon energy of CZS films

\subsection{Electrical Properties of CZS Films}

The electrical properties of CZS thin films were observed utilizing the four-point probe technique. The resistivity $(\rho)$ of the films was determined by Equation (6) [34]:

$\rho=\frac{\pi}{\ln 2} \times \frac{V}{I}(t)$

Here, $I$ is the average current, $V$ is the average voltage and $t$ is the thickness from RBS measurements. The electrical conductivity of the films was taken as the inverse of the electrical resistivity. The overview of the estimated values of the electrical conductivity and resistivity of the films are given in Table 2 . As seen from the table, the resistivity of the films decreased with increasing deposition temperatures, which indicates that the MOCVD deposited films are naturally semiconducting [39, 40]. The observed decrease in the electrical resistivity is due to the improved concentration of the charge carriers within the film's system. This reflects the expansion and pairing of grains to form larger crystallites within the CZS films. Because of this structural modification, the charge carrier density is increased which leads to a decrease in electrical resistivity. Moreover, the obtained values were within the average range of electrical resistivity for semiconducting CZS thin-film materials reported in literatures [3].

Also, from Table 2, it was observed that the electrical conductivity increases from $3.39 \times 10^{-2}$ to $7.38 \times 10$ ${ }^{-2}(\Omega . \mathrm{cm})^{-1}$ with an increase in deposition temperatures. This increase could be the direct result of the reduction in residual defects as well as the crystalline nature of the films (as noticed in Figure 4). Usually, electrical conductivity in semiconducting thin films is dependent on the grain sizes as well as the film thicknesses $[33,41]$. Therefore, in the present study, electrical conductivity increases with an increase in deposition temperatures as well as the film's thickness (Table 1), which may account for more grain scattering occurring in the thinner films than in the thicker films since conductivity is inversely proportional to the frequency of the electron grain scattering $[41,42]$. Thus, increasing conductivity with an increase in CZS thickness and deposition temperature.

\section{CONCLUSION}

CZS composite thin films were grown onto a glass substrate using the MOCVD technique at varying temperatures $\left(370^{\circ} \mathrm{C}, 400^{\circ} \mathrm{C}, 430^{\circ} \mathrm{C}\right.$ and $\left.470^{\circ} \mathrm{C}\right)$ to determine the influence of the deposition temperatures on the structural, elemental, optical as well as the electrical properties. The results predicted that the variation in deposition temperature is controlling the phenomena for the physical features of deposited CZS 
thin film. The RBS measurement confirmed that the films comprise of $\mathrm{Zn}, \mathrm{Cu}$ and $\mathrm{S}$ in various elemental compositions with stoichiometry that was controlled by the deposition temperatures having a thickness that ranged between 51.00 to $63.00 \mathrm{~nm}$.

The SEM data of the deposited films show different morphologies with several grains that increased with deposition temperature. Also, optical characterization shows that the films displayed a direct transition with an energy gap that varies from 1.79 to $2.10 \mathrm{eV}$. For CZS film deposited at $470{ }^{\circ} \mathrm{C}$, the maximum electrical conductivity was $7.38 \times 10-2(\Omega . \mathrm{cm})^{-1}$ and minimum electrical resistivity was $1.35 \times 10^{1}(\Omega . \mathrm{cm})$. The SEM revealed an agglomeration of Dn with different morphological forms. The films exhibited high absorbance in the UV region with an energy gap that decreased with an increase in deposition temperatures. The refractive index and extinction coefficient showed that the optical constants of the deposited material were influenced by temperature. Current-voltage measurements suggest that the deposited films are naturally semiconducting. The Dn varies with different temperatures and there reduces as the temperature was increased from $370^{\circ} \mathrm{C}$ to $470^{\circ} \mathrm{C}$. Furthermore, the deposition temperature is a key factor in controlling the growth rate.

Overall, the MOCVD technique allows a simplified synthesis of the material while maintaining exceptional control over the structural, elemental, optical and electrical properties of the thin films. The films exhibited high absorbance in the UV region with an energy gap that decreased with an increase in deposition temperatures. The refractive index and extinction coefficient showed that the optical constants of the deposited material were influenced by temperature. Hence, the current-voltage measurements suggest that the deposited films are naturally semiconducting and there is the possibility of using copper and zinc dithiocarbamate precursors in depositing high-quality CZS thin films with comparable properties.

\section{CONFLICTS OF INTEREST}

No conflict of interest was declared by the authors.

\section{ACKNOWLEDGEMENT}

The authors are grateful to their respective institutions and to the entire staff and students of the Department of Physics and Engineering Physics, Obafemi Awolowo University, Ile-Ife, Osun State, Nigeria for allowing the use of their facility for the production of the CZS films.

\section{REFERENCES}

[1] Omran Alkhayatt, A. H., Habieb, A. A., Al-Noaman, A. H. A., Hameed, A. A., "Structure, surface morphology and optical properties of $\mathrm{Cu}_{\mathrm{x}} \mathrm{Zn}_{1^{-} \mathrm{x}} \mathrm{S} / \mathrm{Au}$ NPs layer for photodetector application", Journal of Physics: IOP Conference Series, 1234: 12012, (2019).

[2] Kitagawa, N., Ito, S., Nguyen, D., Nishino, H., "Copper zinc sulfur compound solar cells fabrication by spray pyrolysis deposition for solar cells", Natural Resources, 4: 142-145, (2013).

[3] Emegha, J. O., Damisa, J., Efe, F. O., Olofinjana, B., Eleruja, M. A., Azi, S. O., "Preparation and characterization of metal organic chemical vapour deposited copper zinc sulphide thin films using single solid source precursors", European Journal of Materials Science and Engineering, 4(1): 11$22,(2019)$.

[4] Ukhurebor, K. E., Azi, S. O., Aigbe, U. O., Onyancha, R. B., Emegha, J. O., "Analysing the uncertainties between reanalysis meteorological data and ground measured meteorological data", Measurement, 165: 108110, (2020).

[5] Hassan, I. A., "Solar Energy Conversion by Photoelectrochemical Processes", PhD Thesis, University of Bath, UK, 1-35, (2011). 
[6] Hossain, M. S., Kabir, H., Rahman, M. M., Hasan, K., Bashir M. S., Rahman, M., Gafur, M. A., Islam, S., Amri, A., Jiang, Z. T., Altarawneh, M., Dlugogorski, B.Z., "Understanding the shrinkage of optical absorption edges of nanostructured Cd-Zn sulphide films for photothermal applications", Applied Surface Science, 392: 854-862, (2017).

[7] Damisa, J., Olofinjana, B., Ebomwonyi, O., Bakare, F., Azi, S. O., "Morphological and optical study of thin films of CuAlS2 deposited by metal organic chemical vapour deposition technique", Materials Research Express, 4: 86412, (2017).

[8] Uhuegbu, C. C., Babatunde, E. B., "Spectral analysis of copper zinc sulphide ternary thin film grown by solution growth technique", American Journal of Scientific and Industrial Research, 1(3): 397-400, (2010).

[9] Rosado-Mendoza, M., Oliva, A. I., "Chemical bath deposition of zinc sulfide films doped with copper”, Materials and Manufacturing Processes”, 31(11): 1454-1460, (2016).

[10] Ortiz-Ramon, D.E., Gonzalez, L.A., Ramirez-Bon, R., "P-type transparent Cu doped ZnS thin films by the chemical bath deposition method", Materials Letters, 124: 267-270, (2014).

[11] Shujah, T., Butt, A., Ikram, M., Shabbir, S., Ali, S., "Effect of deposition temperature variation on thin films synthesis via AACVD", Digest Journal of Nanomaterials and Biostructures, 11(3): $891-898,(2016)$.

[12] Olofinjana, B., Egharavbe, G., Taleatu, B., Akinwunmi, O., Ajayi, E. O., "MOCVD of molybdenum sulphide thin film via single solid source precursor bis-(morpholinodithioato-s,s')mo", Journal of Modern Physics, 2: 341-349, (2011).

[13] Eleruja, M. A., Adedeji, A.V., Olofinjana, B., Akinwunmi, O. O., Ojo, I. A. O., Egharavbe, G. O., Osasona, O., Ajayi, E. O. B., "Preparation and characterization of mercury cadmium sulphide thin films", Journal of Non-oxide Glasses, 2(4): 175-182, (2010).

[14] Osuntola, K. O., "Preparation and characterization of metal organic chemical vapour deposited (MOCVD) thin films of metal sulphides", MSc Thesis, Obafemi Awolowo University, Nigeria, $1-10,(1990)$.

[15] Jose, E., Santhosh Kumar, M. C., "Room temperature deposition of highly crystalline Cu-Zn-S thin films for solar cell applications using SILAR method", Journal of Alloys and Compounds, 712: 649-656, (2017).

[16] Nagamani, K., Reddy, M. V., Lingappa, Y., Ramakrishna Reddy, K., Miles, T. R.W., "Physical properties of ZnxCd1-xS nanocrystalline layers synthesized by solution growth method", International Journal of Optoelectronic Engineering, 2: 1-4, (2012).

[17] Gardew, D. D., Abza, A. T., Gashaw, H. F., "Synthesis and characterization of copper zinc sulfide $\left(\mathrm{Cu}_{-} \mathrm{x} \mathrm{Zn}_{-}(1-\mathrm{x}) \mathrm{S}\right)$ ternary thin film by using acidic chemical bath deposition method", International Journal of Thin Film Science and Technology, 10(1): 4, (2021).

[18] Sreedhar, M., Neelakanta, R. I., Bera, P., Shyju, T. S., Anandan, C., "Studies of Cu-doped ZnS thin films prepared by sputtering technique", Surface and Interface Analysis, 49(4): 284-290, (2017).

[19] Mukherjee, A., Mitra, P., "Characterization of Sn doped $\mathrm{ZnS}$ thin films synthesized by CBD”, Materials Research, 20: 430-435, (2017). 
[20] Kassim, A., Nagalingam, S., Min, H. S., Karrim, N., "XRD and AFM studies of ZnS thin films produced by electrodeposition method", Arabian Journal of Chemistry, 3(4): 243-249, (2010).

[21] Helmentine, A.M., "Heat of formation table for common compound, ThoughtCo". https://www.thoughtco.com/common-compound-heat-of-formation-table-609253. Access date: 02.01 .2021

[22] Aigbe, U. O., Onyancha, R. B., Ukhurebor, K. E., Obodo, K. O., "Removal of fluoride ions using polypyrrole magnetic nanocomposite influenced by rotating magnetic field", RSC Advances, 10(1): 595-609, (2020).

[23] Efe, F. O., Olofinjana, B., Fasakin, O., Eleruja, M. A., Ajayi, E. O. B., "Composition, structural, morphological, optical and electrical property evolution in mocvd $\mathrm{Cu}-\mathrm{Zn}-\mathrm{S}$ thin films prepared at different temperature using a single solid source precursor", Journal of Electronic Materials, 48(12): 1-14, (2019).

[24] Olofinjana, B., Adebisi, A. C., Efe, F. O., Fasakin, O., Oyedotun, K. O., Eleruja, M. A., Ajayi, E. O. B., Manyala, N., "Single solid source precursor route to the synthesis of MOCVD Cu-Cd-S thin films", Materials Research Express, 6(10): 106442, (2019).

[25] Emegha, J. O., Olofinjana, B., Eleruja, M. A., Efe, F. O., Azi, S. O., "A detailed study on preparation and some physical properties of $\mathrm{Cu}_{\mathrm{x}} \mathrm{Zn}_{1^{-} \mathrm{x}} \mathrm{S}$ thin films deposited by metal organic chemical vapour deposition technique", In: Goel, A.K., (ed.), Recent Developments in Engineering Research, 8, Book Publisher International, West Bangal, India, 44-53, (2020).

[26] Olofinjana, B., Egharevba, G. O., Taleatu, B. A., Akinwunmi, O. O., Ajayi, E. O. B., "Effect of deposition temperature on some properties of MOCVD molybdenum sulphate thin films", Materials Science \& Engineering B, 4(4): 78-85, (2014).

[27] Govindasamy, G., Murugasen, P., Sagadevan, S., "Optical and electrical properties of chemical bath deposited cobalt sulphide thin films", Journal of Materials Research, 20(1): 62-67, (2017).

[28] Emegha, J. O., Damisa, J., Elete, D. E., Arijaje, T. E., Akinpelu, A., Ogundile, P. O., Onumejor, C. A., "Growth and characterization of copper cadmium sulphide thin film", Journal of Physics: IOP Conference Series, 1734: 12045, (2021).

[29] Chowdhury, F., Firoz Hasan, S. M., Sahabul Alam, M., "Morphological and optical properties of vacuum evaporated $\mathrm{ZnO}$ thin films", Turkish Journal of Physics, 36: 1-7, (2012).

[30] Ezenwa, I. A., Okoli, N. L., "Characterization of chemically synthesized copper zinc sulphide $\left(\mathrm{CuZnS}_{2}\right)$ thin films”, European Physical Journal Applied Physics, 1(1):1-9, (2015).

[31] Uhuegbu, C. C., Babatunde, E. B., Oluwafemi, C. O., "The study of copper zinc sulphide $\left(\mathrm{CuZnS}_{2}\right)$ thin films", Turkish Journal of Physics, 32: 39-47, (2008).

[32] Ompong, D., "Investigating the Optical Properties of Cd1 ${ }_{-x} Z_{x} S$ Thin Films Deposited by the Dip Technique", MSc Thesis, Kwame Nkrumah University of Science and Technology, Ghana, 1-30, (2010).

[33] Jassim, S. A., Rashid Ali Zumaila, A., Abdella Ali Al Waly, G., "Influence of substrate temperature on the structure, optical and electrical properties of CdS thin films deposited by thermal evaporation", Results in Physics, 3: 173-178, (2013). 
[34] Al-Taa'y, W.A., Oboudi, S. F., Yousif, E., Nabi, M. A., Yusop, R. M., Derawi, D., "Fabrication and characterization of nickel chloride doped PMMA films", Advances in Materials Science and Engineering, 913260: 1-5, (2015).

[35] Demir, R., Gode, F., Guneri, E., Emen, F. M., "The effect of nanoparticle sizes on the structural, optical and electrical properties of indium sulfide thin films consisting of $\operatorname{In}_{2} S_{3}$ and $\operatorname{In}_{6} S_{7}$ phases", Journal of Molecular Structure, 1227: 129565, (2021).

[36] Arslan, M., Habib, A., Zakri, M., Mehmood, A., Husnain, G., "Elemental, structural and optical properties of nanocrystalline $\mathrm{Zn} 1{ }_{\mathrm{x}} \mathrm{Cu}_{\mathrm{x}} \mathrm{Se}$ films deposited by close spaced sublimation technique", Journal of Science: Advanced Materials and Devices, 2: 79-85, (2017).

[37] Alwan, T. J., Jabbar, M. A., "Structural and optical properties of $\mathrm{CuAlS}_{2}$ thin films prepared via chemical bath deposition", Turkish Journal of Physics, 34: 107-116, (2010).

[38] Emegha, J. O., Okafor, C. M., Ukhurebor, K. E., "Optical properties of copper-zinc sulphide network from mixed single solid source precursors of copper and zinc dithiocarbamates", Walailak Journal of Science and Technology, 18(9): 1-11, (2021).

[39] Mohamed, S. H., "Photocatalytic, optical and electrical properties of copper-doped zinc sulfide thin films", Journal of Physics D: Applied Physics, 43(3): 35406, (2010).

[40] Innocenti, M., Becucci, L., Benecista, I., Carretti, E., Cinotti, S., Dei, L., Di Benedetto, F., Lavacchi, A., Marinelli, F., Salvietti, E., Vizza, F., Foresti, M. L., "Electrochemical growth of CuZn sulphides", Journal of Electroanalytical Chemistry, 710: 17-21, (2013).

[41] Emegha, J. O., Olofinjana, B., Ukhurebor, K. E., Adegbite, J. T., Eleruja, M. A., "Electrical properties of semiconducting copper zinc sulphide thin films", Current Journal of Applied Science and Technology, 22(1): 1-9, (2022).

[42] Gode, F., Guneri, E., Emen, F. M., Emir Kafadar, V., Unlu, S., "Synthesis, structural, optical, electrical and thermoluminescence properties of chemically deposited PbS thin films", Journal of Luminescence, 147: 41-48, (2014). 